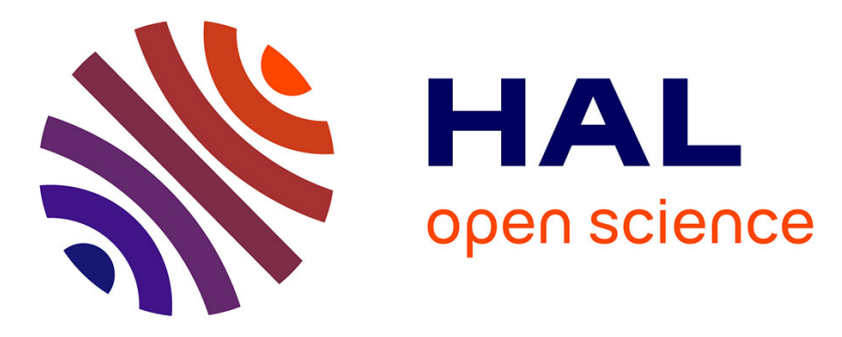

\title{
Construction field monitoring of a cob prototype building
}

\author{
A Azil, M Le Guern, Karim Touati, M Gomina, N Sebaibi, M Boutouil, F \\ Streiff, S Goodhew, H Louahlia
}

\section{- To cite this version:}

A Azil, M Le Guern, Karim Touati, M Gomina, N Sebaibi, et al.. Construction field monitoring of a cob prototype building. 4th International Conference on Bio-Based Building Materials, Jun 2021, Barcelona, Spain. pp.458-465, 10.4028/www.scientific.net/CTA.1.458 . hal-03456324

\section{HAL Id: hal-03456324 \\ https://hal.science/hal-03456324}

Submitted on 30 Nov 2021

HAL is a multi-disciplinary open access archive for the deposit and dissemination of scientific research documents, whether they are published or not. The documents may come from teaching and research institutions in France or abroad, or from public or private research centers.
L'archive ouverte pluridisciplinaire HAL, est destinée au dépôt et à la diffusion de documents scientifiques de niveau recherche, publiés ou non, émanant des établissements d'enseignement et de recherche français ou étrangers, des laboratoires publics ou privés. 
See discussions, stats, and author profiles for this publication at: https://www.researchgate.net/publication/352903804

\section{CONSTRUCTION FIELD MONITORING OF A COB PROTOTYPE BUILDING}

Conference Paper · June 2021

CITATIONS

9 authors, including:

Malo le guern

ESITC Caen

24 PUBLICATIONS 177 CITATIONS

SEE PROFILE

Nassim Sebaibi

ESITC Caen

55 PUBLICATIONS 528 CITATIONS

SEE PROFILE

Some of the authors of this publication are also working on these related projects:

Project SETARMS View project

Project Condenseur à Air à Forte Efficacité Energétique (CAFEE) View project
READS

77

Karim Touati

ESITC Caen

15 PUBLICATIONS 80 CITATIONS

SEE PROFILE 
June $16^{\text {th }}-18^{\text {th }} 2021$

Barcelona, Spain

\title{
CONSTRUCTION FIELD MONITORING OF A COB PROTOTYPE BUILDING
}

\author{
A. Azil' ${ }^{1}$, M. Le Guern ${ }^{1}$, K. Touati ${ }^{1}$, M. Gomina ${ }^{2}$, N. Sebaibi ${ }^{1}$ M. Boutouil ${ }^{1}$, F. Streiff ${ }^{3}$, S. Goodhew ${ }^{4}$, H. Louahlia $^{5}$ \\ ${ }^{1}$ COMUE Normandie Université - Laboratoire de Recherche ESITC Caen, France \\ ${ }^{2}$ CRISMAT, UMR 6508 CNRS, ENSICAEN, France \\ ${ }^{3}$ Parc naturel régional des marais du Cotentin et du Bessin, France \\ ${ }^{4}$ Université de Plymouth, Royaume-Uni \\ ${ }^{5}$ Normandie Université, LUSAC-Unicaen, Site universitaire Bellevue, France \\ ${ }^{*}$ Corresponding author; e-mail: athmane.azil@esitc-caen.fr
}

\begin{abstract}
Cob is an earthen building material made by soil, fibres and water used for millennia. However, cob construction disappeared out during the nineteenth century. These last years, it is experiencing a renaissance in Northwestern France and Southern England. Due to a limited technical knowledge, the investigation of engineering properties is important for modern design practice and code requirements. Moreover, to ensure building properties, it is necessary to have same quality mix along the building phases.

The aim of this study is to determine material variation during the monitoring of a cob prototype building in Normandy (France). This study investigated structural cob mix composition, water content, density, mechanical properties and thermal conductivity. Specimens shape used were cylindrical $\varnothing 110 \times \mathrm{H} 220$ $\mathrm{mm}$ and prismatic $300 \times 300 \times 70 \mathrm{~mm}$.

Results indicated a variation in cob mix (water content, materials proportions) between three different lifts. These variations lead to different densities and, consequently, to variables compressive strengths: 0.99 to $1.38 \mathrm{MPa}$ and thermal conductivities from $0.610-0.816 \mathrm{~W} \cdot \mathrm{m}^{-1} \cdot \mathrm{K}^{-1}$.
\end{abstract}

\section{Keywords:}

Cob; monitoring; prototype building; density; compressive strength

\section{INTRODUCTION}

Green construction is a major concern. In the building sector, a growing interest has been observed during the last decades within ecological materials. Like other earth construction techniques, cob has met with renewed interest for its low environmental impact (Morel, et al., 2001) and (Lyn Ford, 2002).

European Buildings consume most of the energy, responsible for $40 \%$ of final energy consumption (Dixit, et al., 2010). The use of local materials as well as the absence of hydraulic cement can reduces the building grey energy. The use of earth as a building material can contribute to the reduction of greenhouse gas emissions, thereby mitigating the risks associated with climate change. In addition, the sorption and evaporation capacity of the earth material allows for temperature harmonization and air filtering (Röhlen et al., 2013).

There is limited literature on monitoring cob mix during construction of a real building. Knowing the material variability will allow to ensure building properties throughout the construction phase. This will help to satisfy modern design practices and code requirements.

To the best of our knowledge, there is no normalized procedure to determine the mechanical performance of cob. Indeed, various specimen production protocols exist with differences in terms of size, mold, mix preparation, drying and water conditioning before testing (Harries et al., 1995; Addison Greer, 1996; Keefe, 2005; Pullen and Scholz, 2011; Vinceslas et al., 2018). It must be noted that uniaxial compressive strength (UCS) and Young's modulus (E) of cob is most often carried out on double slenderness cylindrical specimens. The mechanical resistance of cob affects the wall height, which reduces construction time and cost (Hamard et al., 2016).

The aim of this work is to monitor the material variation during the building of a cob prototype in Normandy (France).

The study is based on the analysis of structural cob mix composition, water content, density, mechanical properties and thermal conductivity. Specimens used were cylindrical $(\varnothing 110 \times \mathrm{H} 220 \mathrm{~mm})$ and Prismatic $(300 \times$ 300 x70 mm) shape. 
This scale 1 prototype building is part of the European Interreg project CobBauge (Fig.1). The main objective of this project is to build a prototype complying with the French thermal regulation.
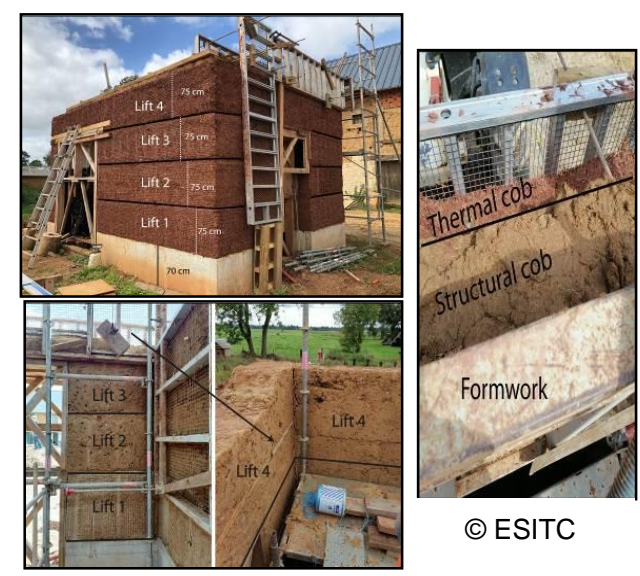

(C) ESITC

Fig. 1: outdoor and indoor view of the earth-based building

The earth, prototype building will have a total area of $20 \mathrm{~m}^{2}$ for an indoor area of $13 \mathrm{~m}^{2}$. The soil-fibre walls will be built on a $70 \mathrm{~cm}$ high composite sub-base made of light concrete and thermopierre. This sub-base structure ensures the same thermal resistance of the soil-fibre walls. The earth, prototype building is also intended to establish the various constructive details to be used for this type of material. The ground plan of the building shows two different layers in the walls, structural cob indoor, and thermal cob outdoor with two different thicknesses used, $70 \mathrm{~cm}$ in the North and East for better thermal insulation and $50 \mathrm{~cm}$ in the South and West more exposed to solar radiation (Fig.1 and 2).

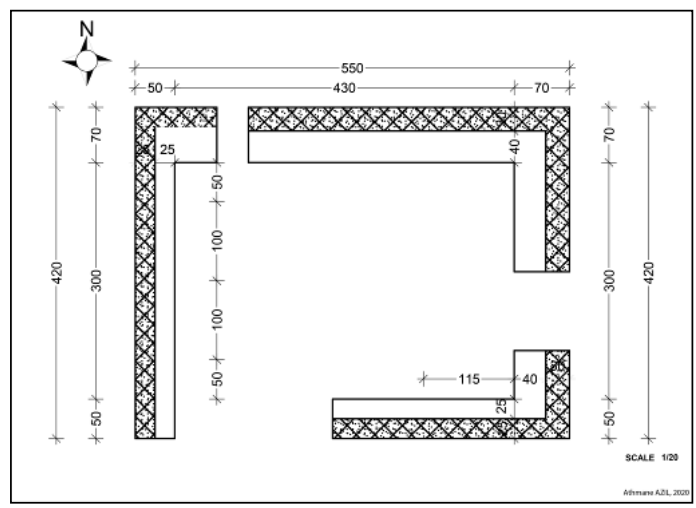

Fig. 2: Ground plan of the earth-based building

\section{MATERIALS AND METHODS}

\subsection{Materials}

The structural cob is made with a mix of two soils (soil 1 and soil 2) and flax straw. Soils were characterized according to their particle size and their clay activity. Particle size analysis was performed by mechanical sieving up to $80 \mu \mathrm{m}$ according to the standard XP P94-041 and by laser grain size for particles under $80 \mu \mathrm{m}$ following the standard ISO 13320. The two soils particle size distribution is presented in Fig.3. Soil 1 has a high fine fraction $(\approx$ $85 \%)$. That fine fraction leads to the use of soil 2 as a granular corrector. The clay activity was determined according to blue value test with respect to the standard NF P94-068 and Atterberg's limit by following the standard NF P94-051 (Tab.1). Logically, soil 1 presents a higher clay activity than soil 2 . The soils used were classified according to the LCPC-USCS classification.

Tab. 1: Soils properties

\begin{tabular}{ccccccc}
\hline Soil & $\begin{array}{c}\text { Nature of soil } \\
\text { (USCS) }\end{array}$ & $\begin{array}{c}\mathbf{W}_{\mathbf{L}} \\
(\%)\end{array}$ & $\begin{array}{c}\mathbf{W}_{\mathbf{p}} \\
(\%)\end{array}$ & $\begin{array}{c}I_{\mathbf{p}} \\
(\mathbf{g} / \mathbf{1 0 0} \mathbf{g})\end{array}$ & $\begin{array}{c}\varnothing<\mathbf{8 0} \\
\boldsymbol{\mu m}\end{array}$ \\
\hline Soil $\mathbf{1}$ & Little plastic silt & 29 & 25 & 4 & 2.19 & 85 \\
Soil $\mathbf{2}$ & Silty sand & 23 & 21 & 2 & 1.97 & 37 \\
\hline
\end{tabular}




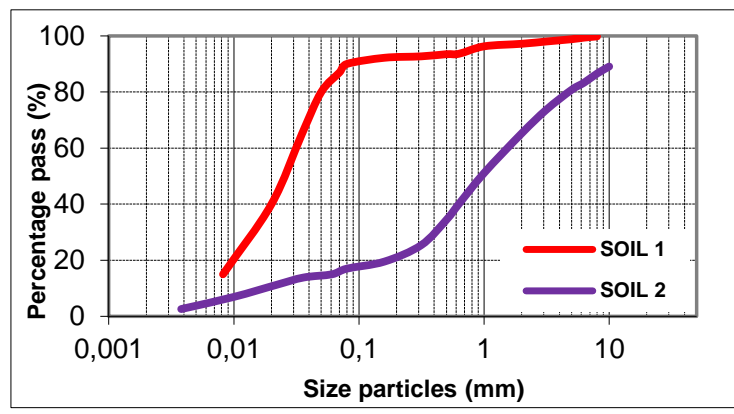

Fig. 3: Granulometric curve of the studied soils

Fibre used in this study is natural flax straw, see Fig.4, they shows water absorption of $431 \%$ after 24 hours, see Fig.5. This characteristic influences the mix properties at fresh state (absorption of available water) and at long term (hygrometric balance). Tensile strength tests on flax straw fibre were carried out under ambient conditions. Fibres of flax straw with $10 \mathrm{~cm}$ length were used to measure the tensile strength. The maximum tensile strength is $112 \mathrm{MPa}$ (Phung, 2018). The average absolute density of flaw straw is $1300 \mathrm{~kg} / \mathrm{m}^{3}$.

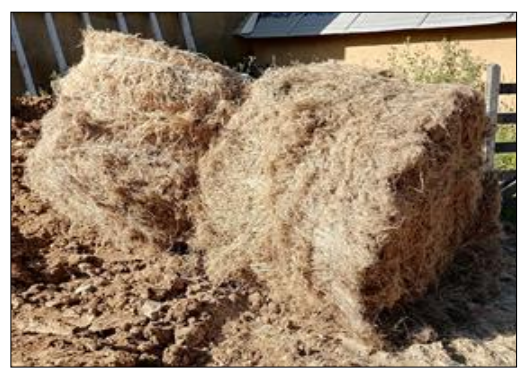

Fig. 4: Natural flax straw

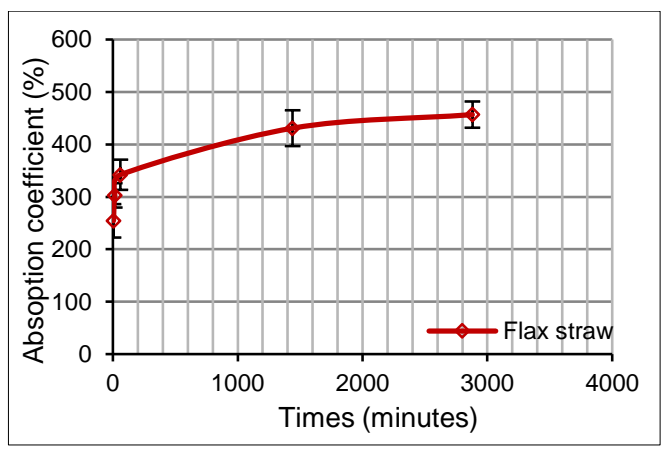

Fig. 5: Absorption coefficient curve of flax straw

\subsection{Mix design and experimental tests}

\section{- Mix and manufacturing specimens}

According to the amount of mix needed for the building prototype, a mechanical digger was used to accelerate the mixing process (Fig.6). The theoretical formulation of cob mix is $1 / 3(33 \%)$ of soil $1,2 / 3(65 \%)$ of soil 2 and $2 \%$ of flaw straw fibre. The fibre content is relative to the dry soil mass.
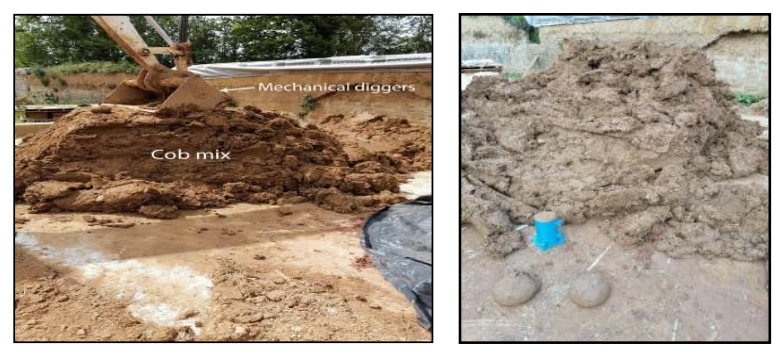

Fig. 6: The cob mixes on the construction site

During the mixing process and building phase, cob mix samples were taken to measure the water content according to the standard NF EN ISO 17892-1, for all the building walls. Specimens were obtained by manual compaction rod. Three cylindrical specimens $(\varnothing 110 \times \mathrm{H} 220 \mathrm{~mm})$ for each lift were used to determine 
compressive strength, apparent density (NF X31-501 Standard) and fibre content (Fig.7). Three prismatic specimens $(300 \times 300 \times 70 \mathrm{~mm})$ for each lift were used to determine apparent density and thermal conductivity (Fig.7). When the cylindrical and prismatic cob specimens were prepared, they were kept in $20 \pm 2{ }^{\circ} \mathrm{C}$ within a relative humidity of $50 \pm 5 \%$ one day and dried at $40^{\circ} \mathrm{C}$ until reaching an equilibrium weight (three consecutive weighing's at 24 hours intervals within $1 \%$ standard deviation).

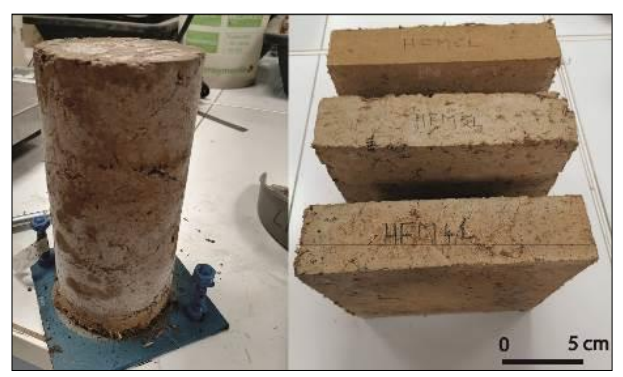

Fig. 7: Cylindrical and prismatic specimens

\section{- Compressive strength and thermal conductivity tests}

Uniaxial compressive strength (UCS) test was carried out using an IGM press, with a capacity of 250 kN (Fig.8). The loading speed used is $0.4 \mathrm{kN} / \mathrm{s}$. Mechanical performance of structural cob is determined for a strain of $2 \%$. This choice was made to have representative values of in-situ material.

Three prismatic specimens $(300 \times 300 \times 70 \mathrm{~mm})$ of each lift were used to measure thermal conductivity of cob with a Heat Flow Meter from Netzsch (HFM 436 Lambda). The measurement was performed at $20^{\circ} \mathrm{C}$ (Fig.8).
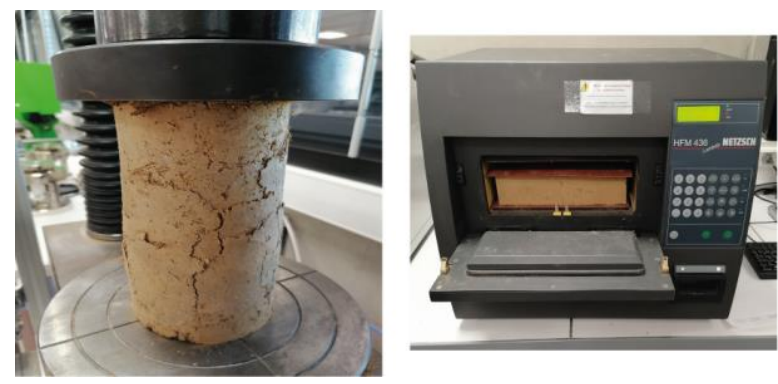

Fig. 8: Compressive strength test (Left) and thermal conductivity test (Right)

\section{- Cob mix and fibre content}

Currently, on-site cob mixing is made using volumetric material estimation. To monitor the mix variation during building, flax straw fibre content was determined.

The experimental protocol consists in dissolving three cylindrical specimens for three lifts, in water and sieving the materials. Sieving size used are 6.3 - 5 - $3.15-2.5-0.9$ and $0.5 \mathrm{~mm}$, see Fig.9.

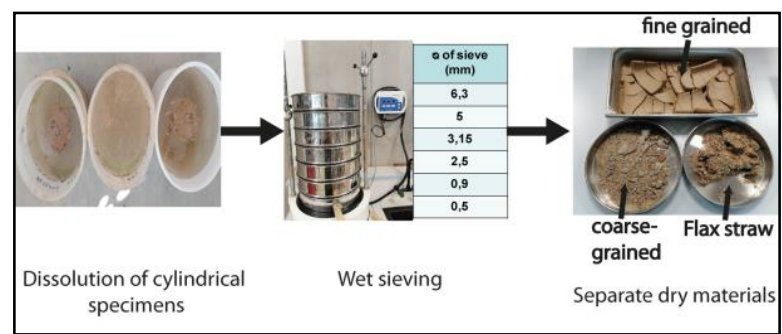

Fig. 9: flax straw fibre and soil separation protocol

\section{RESULTS AND DISCUSSION}

\subsection{Fibre content in cob mix}

In the laboratory, the percentages of flax straw fibre measured for three lifts in relationship with the dry mass of soil are presented in Tab.2.

The cob mixes on the site were done in volumetric estimation, which leads to variations in the amount of fibre in lifts. 
Tab. 2: Fibre content measured in laboratory

\begin{tabular}{ccc}
\hline Lifts & $\begin{array}{c}\text { Specimens } \\
\text { number }\end{array}$ & Fibre content (\%) \\
\hline Lift 2 & 3 & $3.7 \pm 0.2$ \\
\hline Lift 3 & 3 & $2.1 \pm 0.2$ \\
\hline Lift 4 & 3 & $2.3 \pm 0.1$ \\
\hline
\end{tabular}

\subsection{Water content in cob mix and walls}

According to the water contents measured in three cylindrical and three prismatic specimens of three lifts, there is not a significant variation in the water content, with the range of $18.4 \%$ to $21.9 \%$ (Fig. 10 ).

The maximum water content in the walls is $21 \%$, as can be seen in Fig. 11.

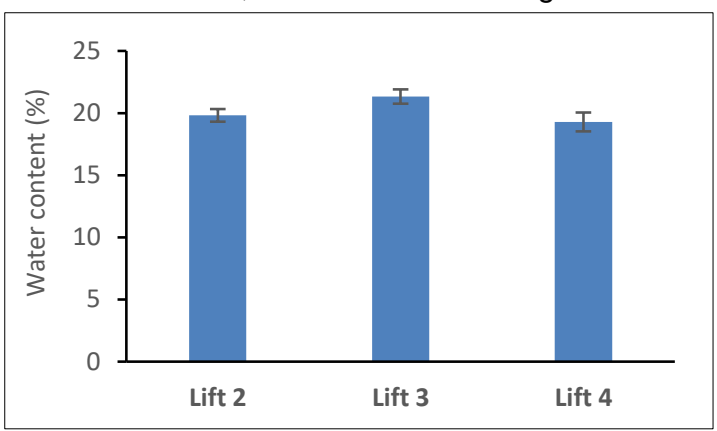

Fig. 10: Average water content of the three lifts

Comparison between water content determined in cylindrical and prismatic specimens (Fig.10) and those measured for walls (Fig.11) confirm that there is not a large variation in water content. This moderate variation is due to the difference of initial water quantity added to the mix on site, building duration of lift ( 2 to 3 days) and weather condition (Temperature and relative humidity).

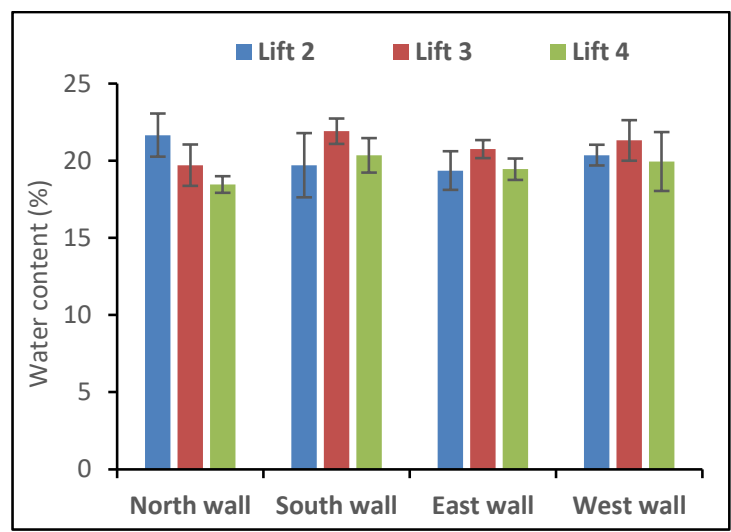

Fig. 11: water content of the different building walls

\subsection{Dry density}

After removal from the mold, they were oven dried at $40^{\circ} \mathrm{C}$ until they reached equilibrium weight; three consecutive weighing's at 24 hours intervals were within $1 \%$ of each other (average 21 days). Densities of cylindrical and prismatic specimens are presented in Tab 3.

Tab. 3: Dry density of cylindrical and prismatic specimens

\begin{tabular}{cccc}
\hline $\begin{array}{c}\mathbf{\rho}_{\text {dry }} \\
\left(\mathbf{k g} / \mathbf{m}^{\mathbf{3}}\right)\end{array}$ & $\begin{array}{c}\text { Sepecimens } \\
\text { number }\end{array}$ & Cylindrical & Prismatic \\
\hline Lift 2 & 3 & $1715 \pm 11$ & $1660 \pm 19$ \\
\hline Lift 3 & 3 & $1763 \pm 22$ & $1762 \pm 13$ \\
\hline Lift 4 & 3 & $1776 \pm 44$ & $1873 \pm 11$ \\
\hline
\end{tabular}


The variation of dry density shown in Fig. 12 is ranging between 1660 and $1873 \mathrm{~kg} / \mathrm{m}^{3}$ in (3) lifts. This variation is probably due to the quantity of fibre in the mix and the material compaction. In lift 2 , the presence of $3.7 \%$ flax straw affects the dry cob and makes it less dense.

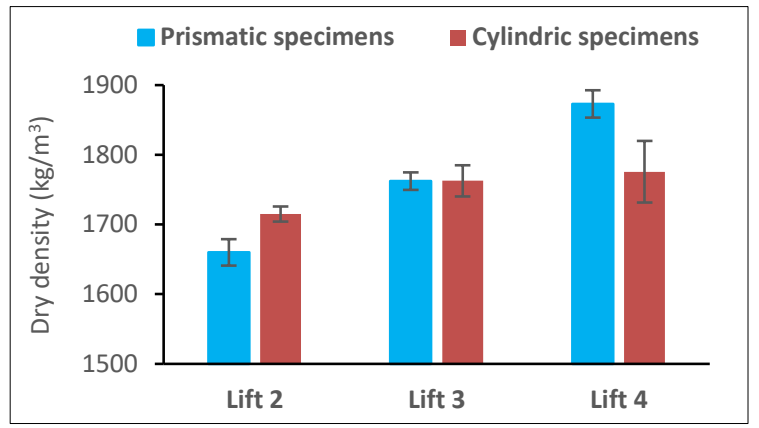

Fig.12: Average dry density of the three lifts

\subsection{Compressive strength and Thermal conductivity}

The compressive strength results are presented in Tab.4 and Fig.13. They have not shown a large variation in maximum compressive strength $\left[\sigma_{(\max )}\right]$ with range of 0.99 to $1.38 \mathrm{MPa}$ and for a strain of $2 \%$ [ $\sigma_{2 \%}$ ] with range of 0.96 to $1.20 \mathrm{MPa}$. Lift 2 presents a low compressive strength compared to the two others, probably due to the high amount of fibre in the mix and the compaction. According to the New Zealand earth construction standard NZS 4298 [New Zealand Standards 1998], the shape of specimen, height to thickness ratio is 2.0, representing aspect ratio factor $\left(\mathrm{K}_{\mathrm{a}}\right)$ of 0.80 , specified by the standard NZS 4298 . With:

$\sigma$ NZS $4298=\sigma_{(\max )} * 0.7 / 0.8$.

The compressive strength results in three lifts are close to the minimum value "1.3 MPa" of New Zealand Standards 1998.

Tab. 4: Dry density and compressive strength in 3 lifts

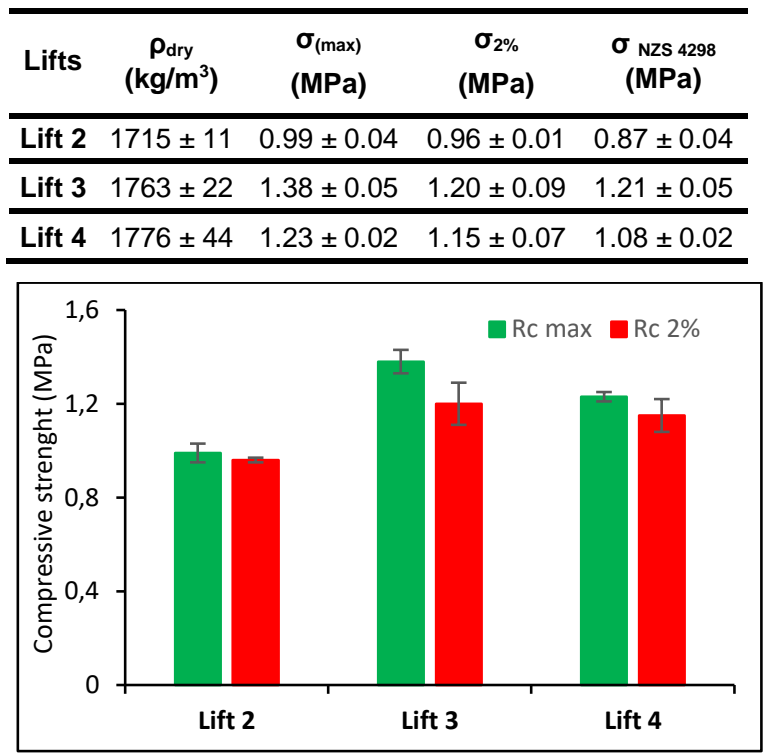

Fig. 13: compressive strength of the three lifts

The results of thermal conductivity measurement present values ranging between $0.610-0.816 \mathrm{~W} \cdot \mathrm{m}^{-1} \cdot \mathrm{K}^{-1}(\mathrm{Fig} .14)$. This variation of thermal conductivity results is in a relationship with a dry density of the prismatic specimens. 


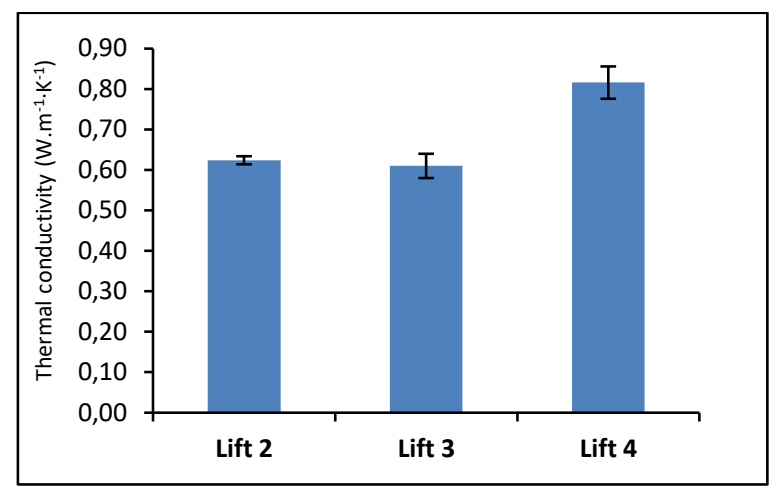

Fig. 14: Cob thermal conductivity in 3 different lifts

\section{CONCLUSION}

In this paper, monitoring and analysis of cob mixes have been done with control of four parameters: water content, dry density, compressive strength, and thermal conductivity. Results show that:

$\checkmark$ Mix variations during construction lead to different densities and, consequently, to variable maximum compressive strengths range from 0.99 to $1.38 \mathrm{MPa}$ and thermal conductivities from 0.610 to $0.816 \mathrm{~W} \cdot \mathrm{m}^{-1} \cdot \mathrm{K}^{-}$ 1.

$\checkmark$ The variation in water content did not have a significant effect on the compressive strength, but it may affect the performance of the mixture throughout the contact between lifts. Particularly during drying, creating cracks.

The monitoring of cob during three different lifts achieved by material characterizations can give a clear idea about the real mechanical and thermal performances of the prototype building; also, the preparation of homogenous and similar cob mix for each lift is important to ensure similar building properties. This work will continue all along the prototype building.

\section{ACKNOWLEDGMENTS}

This work is part of the CobBauge project selected by the European cross-border cooperation program INTEREG V France-(Channel)-England. The authors would like to thank the ERDF for the financing of this work.

\section{REFERENCES}

Addison Greer, M. J., 1996. The effect of moisture content and composition on the compressive strength and rigidity of cob made from soil of the Breccia Measures near Teignmouth, Devon, PhD. Plymouth School of Architecture. doi: 10.1029/2003GL016963.

Dixit, M. K., Fernandez-solis, J., Lavy, S., and Culp, C. H., 2010. Identification of parameters for embodied energy measurement: a literature review, Energy and Building, 42, pp. 1238-1247, doi.org/10.1016/j.enbuild. 2010.02.016.

Evans, I., Smith, M. G., and Smiley, L., 2002. The Hand-Sculpted House: A Practical and Philosophical Guide to Building a Cob Cottage, Chelsea Green Publishing Company, White River Junction, Vermont.

Harries, R., Saxton, B. and Coventry, K. 1995. The geological and geotechnical properties of earth material from central Devon in relation to its suitability for building in "Cob"', Geoscience in South-West England, 8(4), pp. 441444.

ISO 13320, 2020. Particle size analysis - Laser diffraction methods.

Keefe, L., 2005. Earth Building - Methods and materials, repair and conservation. Abingdon (UK): Taylor \& Francis Group.

Lyn Ford, M., 2002. The Development of a Methodology for Creating an Earthen Building Inventory, PhD, University of Plymouth. https://pearl. plymouth.ac.uk/handle/10026.1/1115.

Morel, J.C., Mesbah, A., Oggero, M., and Walker, P., 2001. Building houses with local materials, means to drastically reduce the environmental impact of construction. Building and Environment 36, 1119-1126. https://doi.org/10.1016/S0360-1323(00)00054-8

NF EN ISO 17892-1, 2014. Geotechnical investigation and testing - Laboratory testing of soil - Part 1: determination of water content.

NF P94-068. AFNOR, 1998. Soils: investigation and testing. Measuring of the methylene blue adsorption capacity of à rocky soil. Determination of the methylene blue of à soil by means of the stain test.

NF P94-051. AFNOR, 1993. Soil: investigation and testing. Determination of Atterberg's limits. Liquid limit test using Casagrande apparatus. Plastic limit test on rolled thread.

NF X31-501, 1992. Soil quality. Physical methods. Measuring of the bulk density of a undisturbed soil sample. Cylinder method. 
Phung T., 2018. Formulation and characterization of an earth-plant fibre composite. Thesis Normandy University 2018.

Pullen, Q., M. and Scholz, T. V., 2011. 'Index and Engineering Properties of Oregon Cob', Journal of Green Building, 6(2), pp. 88-106. doi: 10.3992/jgb.6.2.88.

Röhlen, U., Ziegert, C., and Mochel, A., 2013. Construire en terre crue : construction, rénovation, finitions. Paris: Éd. "Le Moniteur.

Smith, M., 2000. "Cob," Alternative Construction: Contemporary Natural Building Methods, edited by Lynne Elizabeth and Cassandra Adams, pp 117-150, John Wiley and Sons, Inc.

Standards New Zealand, 1998. Materials and Workmanship for Earth Buildings. NZS 4298. Wellington: 1998.P.24.

Vinceslas, T., Hamard, E., Razakamanantsoa, A., and Bendahmane, F.; 2020. 'Further development of a laboratory procedure to assess the mechanical performance of cob', Environmental Geotechnics, (2020), pp. 1-8. doi: 10.1680/jenge.17.00056.

XP P94-041. AFNOR,1995. Soils: recognition and testing - granulometric identification - wet sieving method. 